\title{
Self-Inflicted Nailgun-Induced Penetrating Penile Injury: Case Report and Discussion
}

\author{
Jeremy Mark Hernandez, MD, PhD*; David Hamilton, MD*; Suneel Upadhye, MD, MSc*
}

\begin{abstract}
Penetrating penile injuries occur mostly in industrial/work accidents, automobile accidents, or as a result of sexual curiosity and attempts at self-expression/mutilation. In this case report, the authors describe an accidental nailgun injury to the penis of a 46-year-old man. We discuss the management of such injuries in the emergency department, including the utility of a dorsal penile block for regional anesthesia. Although exceptionally rare, familiarity with penetrating lower urinary tract injuries may reduce their long-term repercussions on genitourinary and sexual health.
\end{abstract}

\section{RÉSUMÉ}

Les plaies pénétrantes du pénis surviennent généralement dans les accidents de travail ou les accidents d'automobile, ou encore sont le fruit de la curiosité sexuelle et de tentatives d'automutilation ou d'expression de soi. Dans le cas décrit ici, les auteurs font état d'une blessure accidentelle du pénis causée par une cloueuse automatique chez un homme de 46 ans. II sera question dans I'article du traitement de ce type de blessure au service des urgences, y compris de l'utilité de l'anesthésie locorégionale par blocage du nerf dorsal du pénis. Bien qu'il s'agisse d'événements rares, une bonne connaissance $\mathrm{du}$ bas appareil urinaire peut réduire les répercussions à long terme sur la santé génito-urinaire et la santé sexuelle.

Keywords: Penetrating penile injury, dorsal penile block, lower urinary tract

\section{INTRODUCTION}

Penetrating injuries can occur throughout the lower urinary tract (LUT). They are rare in civilians but common to soldiers during wartime. ${ }^{1,2}$ In the civilian setting, penetrating penile injuries occur mostly in industrial/work accidents, automobile accidents, or as a result of sexual curiosity and attempts at self-expression/mutilation., ${ }^{3,4}$
Not surprisingly, the incidence of penetrating penile injuries is underreported, as many patients do not seek medical attention for emotional, social, or psychological reasons. $^{5}$

Penetrating penile injuries can involve the corpora, urethra, or penile soft tissue. Mechanisms generally involve gunshot wounds, ${ }^{4}$ human/animal bites, ${ }^{6,7}$ and zipper entrapment ${ }^{8,9}$. We are unaware of any previous reports of a nailgun-inflicted penetrating penile injury.

In this case report, we describe an unintentional self-inflicted nailgun injury to the penis. We discuss the management of such injuries in the emergency department (ED), including the utility of a dorsal penile block for regional anesthesia.

\section{CASE PRESENTATION}

\section{History and physical}

A 46-year-old man presented to our tertiary care centre by ambulance with an unintentional penetrating penile injury sustained while working at a construction site. He denied the urge to void since the injury. He was awake, alert, and oriented, and his vital signs were within normal limits. Primary trauma survey revealed a single barbed 3.5" nail (1/4" diameter) inserted obliquely through the glans and exiting dorsally at the shaft, proximal to the corona (Figure 1). Multiple layers of garments were carefully removed using trauma shears in order to fully assess the injury. There were clear entrance and exit points. There was no active bleeding or hematomas, and no signs of scrotal injury or broken nail fragments elsewhere in the area. Tenderness was localized to the area immediately surrounding the entrance and exit wounds.

From the *Division of Emergency Medicine, Department of Medicine, McMaster University, Hamilton, ON.

Correspondence to: Jeremy Mark Hernandez, PGY-3 Resident, Emergency Medicine, Hamilton General Hospital, Division of Emergency Medicine, 2nd Floor, Room 252, 237 Barton Street East, Hamilton, ON, L8L 2X2; Email: jeremy.hernandez@medportal.ca 


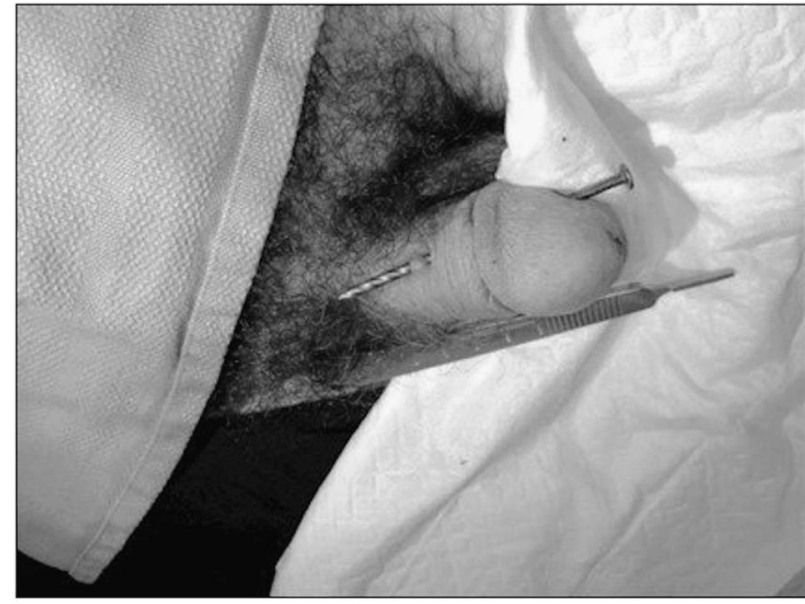

Figure 1. Picture illustrating an unintentional nailguninflicted penetrating penile injury sustained at a construction site.

\section{Management}

The patient was promptly given cefazolin $2 \mathrm{~g} I V$, tetanus toxoid IM, morphine $10 \mathrm{mg} \mathrm{IV}$, and started on maintenance IV crystalloid fluid. Given the patient's local tenderness, a dorsal penile block was performed. The full technique is described in the Discussion section. Briefly, the site of injection was cleansed with chlorhexidine and aseptic technique was utilized to infiltrate $5 \mathrm{~mL}$ of $1 \%$ lidocaine into the right and left dorsal penile nerves at the base of the penis. The nail was removed in the operating room by Urology under a general anesthetic and a direct cystoscopy was performed which confirmed no urethral injury. The procedure was well-tolerated by the patient and he was discharged from hospital that same day following a successful voiding trial.

\section{DISCUSSION}

Previous authors have noted that up to $80 \%$ of penetrating penile injuries had associated injuries, with the most common sites of injury being the proximal lower extremity and scrotum, while urethral injury was the second most common. ${ }^{10,11}$ Except in cases of clearly superficial tangential injuries, a retrograde urethrogram (ordered during initial assessment by the ED physician) or direct cystoscopy (performed by the urologist during surgical exploration in the operating room) is routinely recommended for all penetrating penile injuries to evaluate for possible urethral injury. Both imaging modalities are recommended in urological trauma

\section{Table 1. Clincal Features of a Urethral Injury}

Blood at the meatus

Inability to void

Hematuria and dysuria

Penile, scrotal and/or perineal swelling

High-riding or impalpable prostate

guidelines. ${ }^{2,10}$ Additionally, for patients with isolated genital gunshot wounds and no suspicion of associated major injuries, an abdominal radiograph is also required as part of a complete trauma evaluation.

Immediate exploration of possible anterior urethral injuries is advised except when this is precluded by other life-threatening injuries. ${ }^{2,10}$ Clinical features of urethral injury are listed in Table 1 . With penetrating penile trauma, urological consultation is strongly advised, even for small lacerations and stab wounds, as surgical urethral closure may be required. Small superficial penile lacerations may be primarily approximated with 4-0 chromic or Vicryl ${ }^{\mathrm{TM}}$ absorbable suture. In the case of larger defects or injuries with a high potential for infection (especially bite wounds), a staged repair with urethral marsupialization and a suprapubic catheter may be required. ${ }^{2,10}$ Patients presenting to a rural/community ED (with no readily available Urology service) with a minor penetrating penile injury (i.e., normal urethrogram, able to void, pain free, no blood at the meatus, etc.) should still receive a (non-emergent) urology consultation to monitor for long-term complications of urethral injury, such as urethral stricture formation, erectile dysfunction, and urinary incontinence.

\section{Dorsal penile block}

The penis is innervated by the pudendal nerve (S2-S4). This nerve eventually divides into the right and left dorsal nerves of the penis, passing under the symphysis pubis to travel just below Buck's fascia to provide sensory innervation to the penis. Indications for regional anesthesia of the penis in the ED include: dorsal slit of the foreskin, phimosis reduction, paraphimosis reduction, repair of penile puncture/ lacerations, and release of penile skin entrapped in zippers. Contraindications include: suspected testicular torsion and skin infection at the site of injection. The materials and procedural steps for an ED dorsal penile block are shown in Table 2 and Figure 2. A second 


Table 2. The Dorsal Penile Block
Suggested materials for performing a dorsal penile block
Povidone iodine or chlorhexidine solution
Gauze pads and sterile towels
Local anesthetic solution ( $1 \%$ lidocaine). Maximum dosing: $4.5 \mathrm{mg} / \mathrm{kg}$ of $1 \%$ lidocaine w/o epinephrine and $7 \mathrm{mg} / \mathrm{kg}$ of $1 \%$ lidocaine with
epinephrine
5 ml Syringe
Needles (blunt 18 -gauge and 25 -gauge)
Method for performing the dorsal penile block
1. Have patient lying in supine position
2. Expose genitalia
3. Apply povidone iodine or chlorhexidine solution to the exposed genitalia and scrotum
4. Clean the glans and shaft of the penis with sterile gauze pads
5. Create a sterile field by placing sterile towels around the penis
6. Raise skin wheals at the 2 and 10 o'clock positions at the base of the penis (immediately distal to the symphysis pubis) using a $25-g a u g e$
needle and $1 \%$ lidocaine
7. Insert the needle through the centre of each skin wheal towards the centre of the shaft to a depth of $0.5-1$ cm or until a loss of resistance is
felt, indicating penetration through Buck's fascia
8. Aspirate to ensure that the needle is not in a blood vessel
9. Inject 2.5 cc of $1 \%$ lidocaine at each position. For small children, $0.2-0.4 \mathrm{ml}$ of $1 \%$ lidocaine should be injected at each position using a
smaller gauge (preferably a $30-g a u g e)$ needle.

(A)

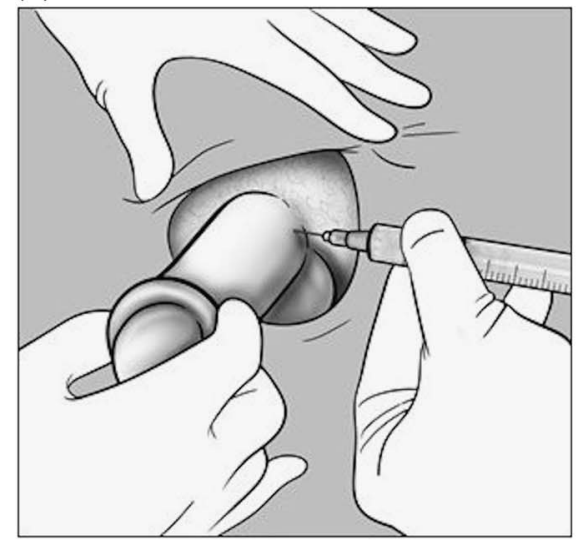

(C)

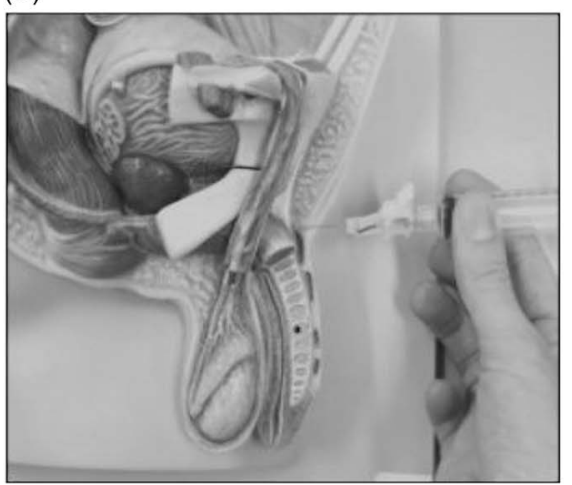

(B)

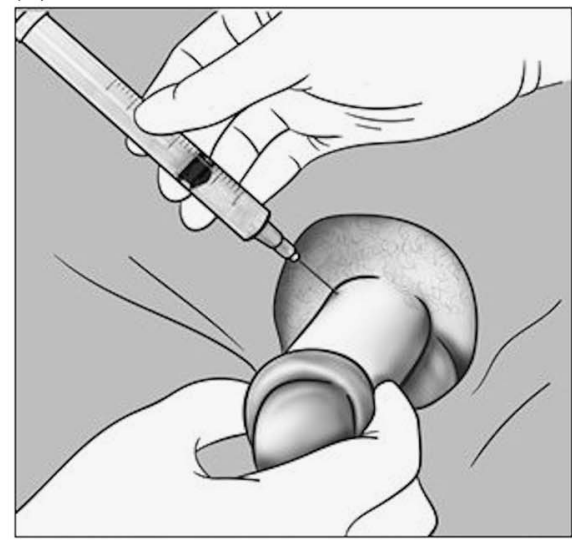

(D)

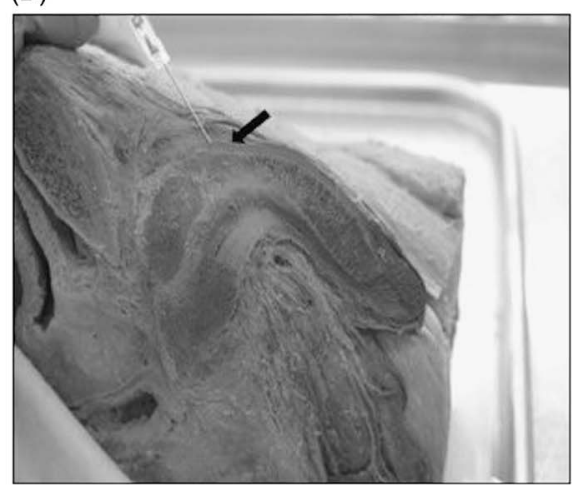

Figure 2. Injection sites for a dorsal penile block: A) 2 o'clock, B) 10 o'clock. Examples depicting the depth of the dorsal penile block injection using $\mathrm{C}$ ) a plastic mannequin and D) a prosected cadaver. The black arrow indicates Buck's fascia. 
method for performing the dorsal penile block utilizing a midline approach is also described in the literature. However, the bilateral approach described here is preferred as it is safer and more likely to produce successful analgesia. ${ }^{12}$

Although traditional teachings have discouraged the use of epinephrine with lidocaine in extremities (including the penis), this practice was more based on theory and opinion than actual evidence. In fact, recent evidence has since debunked this practice. ${ }^{12,13}$ In terms of penile blocks, supplementing $1 \%$ lidocaine with epinephrine has numerous advantages: increased patient satisfaction, low complication rates, improved view of the working field, and an extended effect of the anesthetic with prolonged reduction in pain. ${ }^{14}$ Given the availability of collateral blood flow to the organ through a complex vascular network, the risk of necrosis is minimal and the view that epinephrine should not be used for local analgesia to the penis is outdated.

\section{CONCLUSION}

We report a case of a penetrating penile injury with a large nail that occurred in an industrial work accident. After nail removal, the patient did well and there were no acute complications identified during his in-hospital work-up. The utility of the dorsal penile nerve block is highlighted in this paper. Physicians should be familiar with the technique and indications for this procedure. Furthermore, physicians should be aware of the complications of a penetrating penile injury, as missed injuries can have significant long-term effects on genitourinary and sexual health. Therefore, almost all of these cases warrant prompt urological consultation.

Competing Interests: None declared.

\section{REFERENCES}

1. Cinman NM, McAninch JW, Porten SP, et al. Gunshot wounds to the lower urinary tract: a single-institution experience. 7 Trauma Acute Care Surg 2013;74(3):725-30.

2. Lumen N, Kuehhas FE, Djakovic N, et al. Review of the current management of lower urinary tract injuries by the EAU Trauma Guidelines Panel. Eur Urol 2015;67(5):925-9.

3. Moon SJ, Kim DH, Chung JH, et al. Unusual foreign bodies in the urinary bladder and urethra due to autoerotism. Int Neurourol 7 2010;14(3):186-9.

4. Phonsombat S, Master VA, McAninch JW. Penetrating external genital trauma: a 30-year single institution experience. 7 Urol 2008;180(1):192-5.

5. Krishna Reddy SV, Shaik AB, Sreenivas K. Penile injuries: A 10-year experience. Can Urol Assoc $f$ 2014;8(9-10): E626-31.

6. Gomes CM, Ribeiro-Filho L, Giron AM, et al. Genital trauma due to animal bites. 7 Urol 2000;165(1):80-3.

7. Wolf JS Jr, Turzan C, Cattolica EV, et al. Dog bites to the male genitalia: characteristics, management and comparison with human bites. $f$ Urol 1993;149(2): 286-9.

8. Nolan JF, Stillwell TJ, Sands JP Jr. Acute management of the zipper-entrapped penis. 7 Emerg Med 1990;8(3): $305-7$.

9. Wyatt JP, Scobie WG. The management of penile zip entrapment in children. Injury 1994;25(1):59-60.

10. Mundy AR, Andrich DE. Urethral trauma. Part II: Types of injury and their management. B7U Int 2011;108(5): 630-50.

11. Mundy AR, Andrich DE. Urethral trauma. Part I: introduction, history, anatomy, pathology, assessment and emergency management. BJU Int 2011;108(3):310-27.

12. Hafner HM, Rocken M, Breuninger $H$. Epinephrinesupplemented local anesthetics for ear and nose surgery: clinical use without complications in more than 10,000 surgical procedures. I Dtsch Dermatol Ges 2005;3 (3):195-9.

13. Krunic AL, Wang LC, Soltani K, et al. Digital anesthesia with epinephrine: an old myth revisited. $7 \mathrm{Am}$ Acad Dermatol 2004;51(5):755-9.

14. Schnabl SM, Herrmann N, Wilder D, et al. Clinical results for use of local anesthesia with epinephrine in penile nerve block. 7 Dtsch Dermatol Ges 2014;12(4): 332-9. 